\title{
Effect of Integrated Ayurveda and Yoga Therapy (IAYT) on remission management of non-Hodgkin lymphoma: A single case study
}

\author{
Tripathi Satyam*, Shenoy Kiran, Munamarty Bhavani
}

Union Yoga Ayurveda, Singapore

\section{KEY WORDS}

Lymphoma

Yoga

Ayurveda

Meditation

Breathing

*Corresponding Author:

Tripathi Satyam, MD

Union Yoga Ayurveda

Singapore

Contact no: +65 832166170

E-mail: ayur.st@gmail.com

\begin{abstract}
Non-Hodgkin lymphomas are lymphoid malignant neoplasms and the prognosis depends on the staging and response to therapy. Stress is an independent factor which can affect the prognosis of the disease. The purpose of the current case study was to evaluate the impact of Yoga and Ayurveda as complementary therapy on the prognosis of the disease and the effect of the same on perceived stress level. A 36 year patient diagnosed with relapsed Non-Hodgkin Lymphoma (NHL) after receiving 3 rounds of chemotherapy and bone marrow transplant visited Union Yoga Ayurveda Clinic in Singapore for therapy. Perceived stress, complete blood count and hemoglobin were assessed pre and post intervention. A 6 month follow up was also done with similar evaluations. The patient was given holistic Yoga therapy and Ayurveda herbal treatment including patrapindasweda (herbal compress) and pichu (herbal soaked gauze pieces). The patient reported improvement in day to day energy levels and immunity with increase in WBC count. The perceived stress scores also showed distinct improvement post intervention. The current case study suggests that the integrative yoga and Ayurveda therapy was feasible and showed improvement in stress and complete blood count in patients with Non-Hodgkin lymphomas.
\end{abstract}

doi: 10.38205/imcr.010113

\section{Introduction}

Lymphoma, a cancer of lymph nodes is an outcome of abnormal cell mutation, specifically lymphocyte changes, resulting in uncontrolled cell proliferation (1). Hodgkin lymphoma and Non-Hodgkin lymphoma (NHL) are widely known types of lymphomas whose treatment is based on prognosis. According to the World Health Organization (WHO), mortality due to NHL is high in Asia (42.7\%) followed by Europe, North America and Africa. Global cancer data by WHO reveals cancer burden rose to 18.1 million new cases and 9.6 million cancer deaths in 2018. Patients desperate for long term health care are down with economic burden which increases considerably at onset and later stages of this condition (2). Cost of the treatment also includes supportive care and alternative techniques used (3). Diagnosis and treatment of cancer is always manifold with numerous side effects. Surviving cancer implies fear of remission, constant reminder of disease resulting in anxiety, hopelessness and helplessness, which can cause severe psychological distress, physical inabilities; threshold for this differs among patients (4). Stress can alter immunological, neurochemical and endocrine functions. A substantial body of research has investigated the association between stress-related psychosocial factors and cancer outcomes (5). Post-traumatic stress symptoms have been observed in cancer patients in all stages. Suicidal tendencies for cancer patients have been observed in later stages of cancer (5). Many studies prove that stress is the major causative factor for depleting immune cells and decreasing T-cells and natural killer cells which can end up formation of cancer cells in our body (6). Yoga has been a tool to handle the psychological distress, which helps to improve ongoing deterioration of functional quality of life (QoL) in all types of cancer (4). According to Yoga, stress is uncontrolled speed of thought, which can be managed with various techniques that corrects imbalances and brings mastery over the mind and thus it works as mind-body therapy. Various studies have concluded on the effectiveness of Yoga on reducing depression, anxiety and fatigue, which also helps in improving physical and psychosocial quality of life (7). Yoga as complementary and alternative therapy helps oncology patients too, with research backing evidence on improving their quality of life and pain management (4) by working on conceptual framework of the Yoga therapy which helps in managing stress by asanas, pranayama, series of stimulation and relaxation techniques followed by rest which helps in bringing back the lost balance in all five layers -"PanchaKosha" (8). As per Yoga philosophy, stress is an emotional state that begins in manomayakosha (mind layer) of a person that could be triggered by different factors. Yoga technique aims at slowing down the rate of flow of thoughts in the mind. Ayurveda is an ancient Indian system of holistic view of human being, which encompasses health maintenance, restoration of normal functions, disease cure and spiritual approach. The concept of natural immunity "Vyadhikshamatvam" has been explained in Ayurveda as not only the capacity of the body to fight against diseases but also for the body's ability to not allow production of disease, which is defined by Ojas (9). For disease free body condition, 
Ojas has to be restored by various treatments and therapies as mentioned in Ayurveda (10). Yoga and Ayurveda have been used in the current case study to evaluate the effect of the complementary therapy on blood tests and perceived stress scale of patients with Non-Hodgkin's disease.

\section{Case presentation}

A 36 years old patient diagnosed with diffuse large B cell Lymphoma (DLBCL), a Non-Hodgkin Lymphoma in 2016 visited Union Yoga Ayurveda Clinic in Singapore. She underwent 6 rounds of chemotherapy, resulting in remission of the disease in 2017. The cancer relapsed in June 2018 and the patient underwent 3 rounds of chemotherapy along with bone marrow transplant in September 2018, no other medications were given. Patient was discharged from hospital and was advised to rest. She herself was a medical anesthesiologist who wanted to undergo complementary medical intervention. At Union Yoga Ayurveda Clinic, patient was considered clinically fit to undergo the therapy provided at the clinic. The Integrated Ayurveda and Yoga therapy (IAYT) intervention began in January 2019 with screening and consultation by the doctor at the Union Yoga Ayurveda clinic in Singapore. Study conducted is represented in flow chart (Figure 1).

Yoga and Ayurveda intervention with meditation were prescribed. It included Yoga practices, mindfulness relaxation techniques and Ayurveda supplements. Yoga practices included loosening practices, joint movements and sun salutation taught

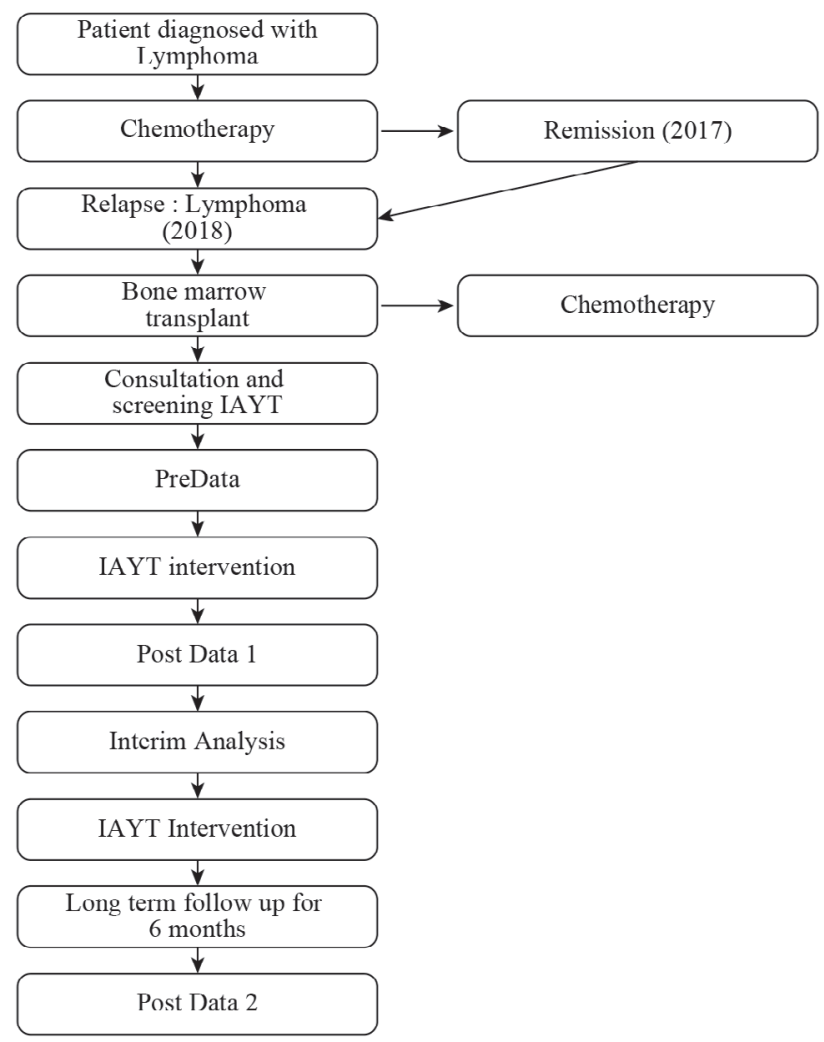

Fig. 1: Design of intervention. by institutionally qualified Yoga therapist. Hypothalamus Pituitary Meditation Technique (HPMT) also known as 'Vijnanana Sadhana Kaushala' was administered, where extreme emotions like happy moments and sad moment are experienced in a mindful way to bring balance on her mood that partially effects T cells and stress (11). Mind Sound Resonance Technique (MSRT), an advanced Yoga technique that uses sound vibration waves was administered which incorporates chanting of A, U, $\mathrm{M}$ and $\mathrm{OM}$ for experiencing the vibrations and resonance at body and mind level (12). Along with these, Pranic Energising Technique (PET) was done by observing and correcting the flow of energy or prana (vital energy) through the body (13). In addition to MSRT and PET, Ayurveda immunotherapy was performed to stimulate the lymph nodes, thymus gland, liver and spleen using herbal oils. An additional treatment of Picchu, cotton gauze dipped in herbal oil and Patra Pinda Sweda (PPS), herbal compress was applied on spine to stimulate the regenerative response (14). Initially, the intensive therapy was done twice a week for a period of 90 mins each per visit per session, but after 8 sessions ( 4 weeks), the sessions were reduced to once a week for 90 mins each time - each visit for the next 6 months follow up.

Therapies were conducted weekly twice followed by which post data- 1 was taken with interim analysis that showed fluctuations in WBC following to which necessary changes in IAYT intervention was done. Therapy continued for 6 months and at the end of 6 months post data- 2 was collected.

Complete blood count including hemoglobin, absolute Leukocyte count, red blood cell count and differential count especially lymphocytes was done (Table 1). In addition to

Table 1: Complete blood count.

\begin{tabular}{|c|c|c|c|}
\hline Hematology & Pre & Post-1 & Post-2 \\
\hline $\begin{array}{l}\text { Total White Blood Count } \\
\left(10^{9} / \mathrm{L}\right)\end{array}$ & 3.6 & 5.1 & 4.8 \\
\hline \multicolumn{4}{|l|}{ Variables \% } \\
\hline Polymorphs & 69.6 & 81 & 78.1 \\
\hline Lymphocytes & 15.8 & 10.1 & 13.3 \\
\hline Monocytes & 11.7 & 6.9 & 6.1 \\
\hline Haemoglobin (g/dL) & 11.8 & 12.4 & 11.6 \\
\hline PSS & 13 & 11 & 09 \\
\hline \multicolumn{4}{|c|}{$\%$ Percentage change in post data } \\
\hline \multicolumn{2}{|l|}{$\%$ change } & Post- $1(\%)$ & Post-2 (\%) \\
\hline \multicolumn{2}{|c|}{ Total White Blood Count $\left(10^{\wedge} 9 / \mathrm{L}\right)$} & 41.60 & 33.33 \\
\hline \multicolumn{4}{|l|}{ Variables \% } \\
\hline Polymorphs & & 16.37 & 12.21 \\
\hline Lymphocytes & & -36.07 & -15.82 \\
\hline Monocytes & & -41.02 & -47.86 \\
\hline Hemoglobin $(\mathrm{g} / \mathrm{dL})$ & & 5.08 & -1.69 \\
\hline PSS & & $-15.38 \%$ & -30.76 \\
\hline
\end{tabular}

(-) Minus denotes decrease in percentage from the pre data. 
that, Perceived Stress Scale (PSS) was also used to examine the pre and post stress levels. The assessment was conducted by an independent, nationally accredited lab in Singapore. The investigator and the treating Physician had no role in the evaluation and analysis of the patients report.

After the intensive therapy, the overall results were very encouraging that complementary therapy of IAYT was very effective. Absolute total WBC count improved from 3.6 per $\mu \mathrm{L}$ to 5.1 per $\mu \mathrm{L}$ and in long term 6 months therapy with follow up, it decreased but still maintained in normal range limit (4.8 per $\mu \mathrm{L})$. This shows that complementary therapy of Yoga and Ayurveda has helped to maintain WBC count to be in normal limits as compared to pre-condition (Figure 2). Similar conditions have been seen in differential counts of polymorphs. Monocytes were initially high from the normal healthy range at $11.7 \%$ and were reduced to normal healthy range of $6.1 \%$ after therapy. Whereas, looking into differential percentage of lymphocytes, it was fluctuating on lower level between $15.8 \%$ to $13.3 \%$. Hemoglobin went up after intensive therapy but in long term reduced frequency of therapy, it went down again. This shows that intensive therapy was effective on hemoglobin but reduced frequency was not efficient enough. Stress level based on PSS scale shows reduction after therapy.
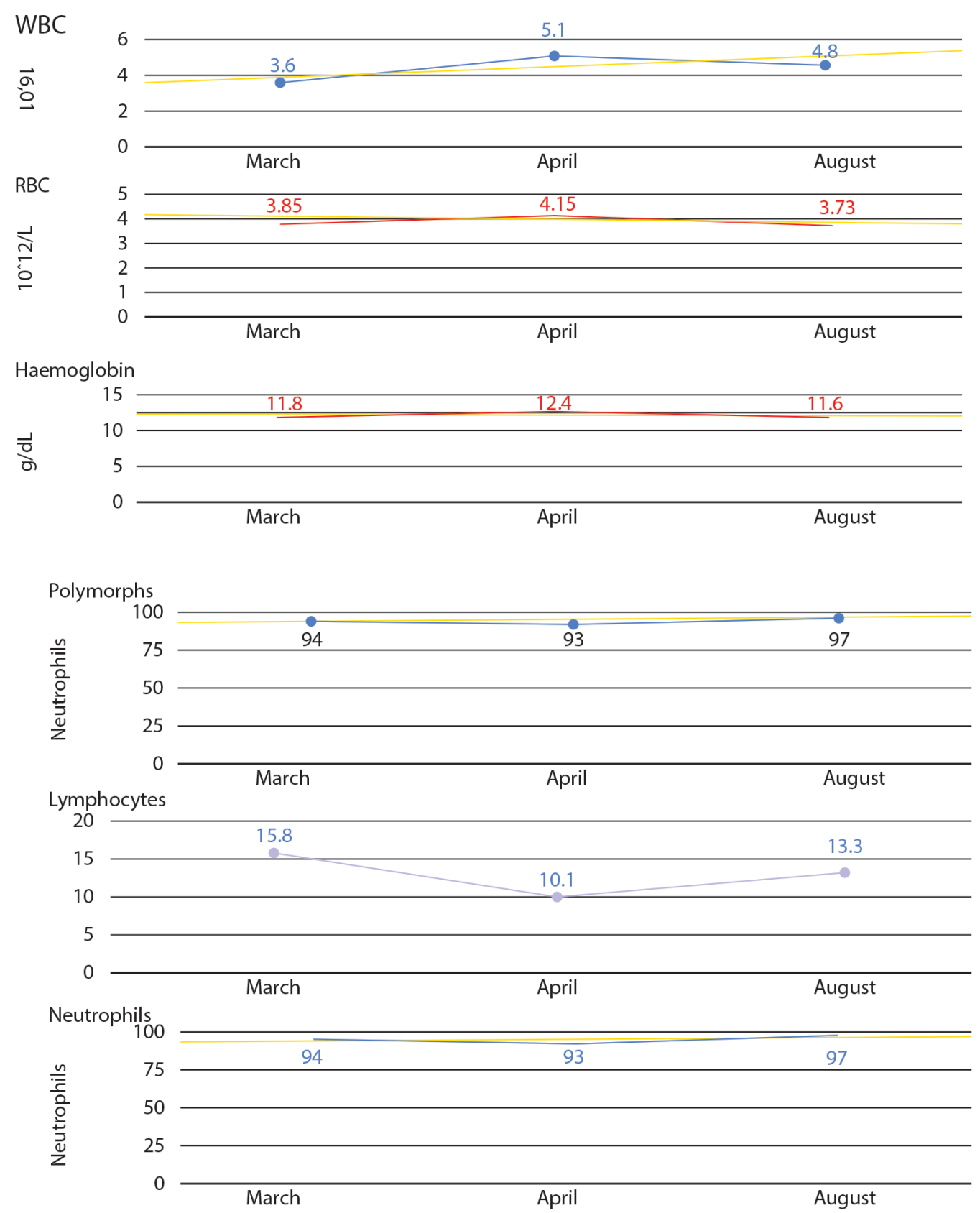

Fig. 2: Improvement in the Complete blood count and Perceived Stress Scale over 6 months. 


\section{Discussion}

Environmental factors, as well as genetic, occupational and dietary factors can contribute to the development of NHL. Spontaneous remission (SR) implies that the T cells i.e. anti-cancer immunity was boosted which may be by host immunological response after chemotherapy. Though in remission, patients can be in constant fear and stressed on recurrences, which might be one of the cause of relapse (15). It has been seen in studies on the immune system that stress, can lead to relapse in SR patients. Constant stress increases the body's sympathetic responses. Stress played a major role in relapse because persistent activation or hyperactivity of the hypothalamic-pituitary-adrenal axis (HPA) as a stress response suppresses the immune response of the body and contributes to the development of some type of cancer or may also cause them to relapse (16). Yoga therapy done at the end of each session acted on HPA by inducing relaxation and activating the parasympathetic system. Nutritional effect of Ayurveda herbs have been found to be affecting the immune system (17) and can add on to the Yoga based effect of countering the stress level. Studies based on psychoneuroimmunology had shown that persistent stress depletes our immune system which is associated with decreased cytotoxic T-cells and natural killer cells which are the body's defense mechanism against cancer cells. Mindful relaxation along with nutrition plays an important role to boost healthy cell growth and improving direct cell nutrition (18). Ayurvedic supplements have shown positive results in the tests as patient was not under any other form of other medication or supplements except ayurvedic herbs. Ashwagandha (Withaniasomnifera) used in Ayurvedic medicine, which contains plant based steroids (withanolide) has been found to have anticancer properties (19). In addition to this, working on HPA axis through yogic relaxation and mindfulness can also alter metabolism (20). All these changes have been observed successfully in early 4 weeks and later in long term follow up of 6 months.

\section{Conclusion}

This case study suggests that IAYT is an effective complementary therapy that can be used for improving health conditions for remission and for post cancer care. Further randomized and controlled trials (RCT) with bigger sample size are warranted to evaluate the efficacy of the therapy and to understand the mechanism behind the same.

\section{Acknowledgement}

This case study is made possible through the help and support from family and friends. Our deep sense of gratitude to Union Yoga and Ayurveda Center for their active and passive support. Last but not the least we would want to extend our appreciation who could not be mentioned here but played their role to inspire us to complete this work.

\section{Author contribution}

ST: led the work from its conception to completion together with diagnosis and prescription of treatment plan with dosage and duration of therapy along with intermediate reviews. SK: Based on contemporary research in this area, SK studied available body of knowledge around the treatment prescribed and compared results from Yoga and Ayurveda therapy treatments. SK is also instrumental in documenting the results and scripting the presis in this case study.

MB: skilled in Yoga and Ayurveda therapy treatment provided the patient with the detailed therapy and charted the observations. All authors discussed the results and contributed to the final manuscript.

\section{Informed consent}

Yes

\section{Conflict of interest}

Study was carried out at the center from where report has been communicated.

\section{Source of funding}

Nil

Received Date: 10-11-19; Revised Date: 03-02-20

Accepted Date: 10-02-20

\section{References}

1. England CG, Rui L, Cai W. Lymphoma: current status of clinical and preclinical imaging with radiolabeled antibodies. Eur J Nucl Med Mol Imaging. 2017 Mar 14;44(3):517-32.

2. Morrison VA, Bell JA, Hamilton L, Ogbonnaya A, Shih H-C, Hennenfent K, et al. Economic burden of patients with diffuse large B-cell and follicular lymphoma treated in the USA. Futur Oncol. 2018 Oct;14(25):2627-42.

3. Bonafede M, Feliciano J, Cai Q Noxon V, Princic N, Richhariya A, et al. Real-world analysis of cost, health care resource utilization, and supportive care in Hodgkin lymphoma patients with frontline failure. Clin Outcomes Res. 2018 Oct; 10:629-41.

4. Rao R, Amritanshu R, Vinutha H, Vaishnaruby S, Deepashree S, Megha M, et al. Role of yoga in cancer patients: Expectations, benefits, and risks: A review. Indian J Palliat Care. 2017;23(3):225.

5. Chida Y, Hamer M, Wardle J, Steptoe A. Do stress-related psychosocial factors contribute to cancer incidence and survival? Nat Clin Pract Oncol. 2008 Aug 20;5(8):466-75.

6. Reiche EMV, Nunes SOV, Morimoto HK. Stress, depression, the immune system, and cancer. Lancet Oncol. 2004 Oct;5(10):617-25. 9

7. Cramer H, Lauche R, Klose P, Lange S, Langhorst J, Dobos GJ. Yoga for improving health-related quality of life, mental health and cancerrelated symptoms in women diagnosed with breast cancer. Cochrane Database Syst Rev. 2017 Jan 3

8. Jagannathan A, Bishenchandra Y. Decoding the integrated approach to yoga therapy. Int J Yoga 2014;7(2):166.

9. Kosta S, Tiwari A, Jain R. Ayurveda and cancer. Pharmacognosy Res. 2010;2(6):393.

10. Science M. Concept of Vyadhikshamatva in Ayurveda- a key for healthy life.2015;425-6.

11. Segerstrom SC, Taylor SE, Kemeny ME, Fahey JL. Optimism is associated with mood, coping, and immune change in response to stress. J Pers Soc Psychol. 1998;74(6):1646-55. 
12. Bhargav H, Metri K, Dhansoia V. Immediate effect of mind sound resonance technique on state anxiety and cognitive functions in patients suffering from generalized anxiety disorder: A self-controlled pilot study. Int J Yoga. 2015;8(1):70.

13. Vadiraja H, Rao R, Nagarathna R, Nagendra H, Patil S, Diwakar R, et al. Effects of yoga in managing fatigue in breast cancer patients: A randomized controlled trial. Indian J Palliat Care. 2017;23(3):247.

14. Dave A, Joshi A, Mehta C, Shukla V. Clinical effect of Nirgundi Patra pinda sweda and Ashwagandhadi Guggulu Yoga in the management of Sandhigata Vata (Osteoarthritis). AYU An Int Q J Res Ayurveda. 2011;32(2):207.

15. Sugiyama T, Arita K, Shinno E, Nakajima T. Spontaneous Remission of Diffuse Large B Cell Lymphoma in the Stomach and the Continuation of Remission for 10 Years. Case Rep Gastroenterol. 2018 Nov 28;12(3):699-703.

16. Bellavance M-A, Rivest S. The HPA-Immune Axis and the Immunomodulatory Actions of Glucocorticoids in the Brain. Front Immunol. 2014 Mar 31;5.
17. Dhruva A, Hecht FM, Miaskowski C, Kaptchuk TJ, Bodeker G, Abrams D, et al. Correlating Traditional Ayurvedic and Modern Medical Perspectives on Cancer: Results of a Qualitative Study. J Altern Complement Med. 2014 May;20(5):364-70.

18. Albers R, Antoine J-M, Bourdet-Sicard R, Calder PC, Gleeson M, Lesourd $\mathrm{B}$, et al. Markers to measure immunomodulation in human nutrition intervention studies. Br J Nutr. 2005 Sep 8;94(3):452-81.

19. Devi PU. Withania somnifera Dunal (Ashwagandha): potential plant source of a promising drug for cancer chemotherapy and radiosensitization. Indian J Exp Biol. 1996 Oct;34(10):927-32.

20. Black DS, Slavich GM. Mindfulness meditation and the immune system: a systematic review of randomized controlled trials. Ann N Y Acad Sci. 2016 Jun;1373(1):13-24. 